University of Wollongong

Research Online

Faculty of Engineering and Information

Faculty of Engineering and Information

Sciences - Papers: Part A

Sciences

$1-1-2015$

Characteristics of power quality disturbances in Australia: Voltage dips at low-voltage sites

Sean T. Elphick

University of Wollongong, elpho@uow.edu.au

Victor W. Smith

University of Wollongong, vic@uow.edu.au

Victor J. Gosbell

University of Wollongong, vgosbell@uow.edu.au

Sarath Perera

University of Wollongong, sarath@uow.edu.au

Philip Ciufo

University of Wollongong, ciufo@uow.edu.au

See next page for additional authors

Follow this and additional works at: https://ro.uow.edu.au/eispapers

Part of the Engineering Commons, and the Science and Technology Studies Commons

Research Online is the open access institutional repository for the University of Wollongong. For further information contact the UOW Library: research-pubs@uow.edu.au 


\title{
Characteristics of power quality disturbances in Australia: Voltage dips at low- voltage sites
}

\author{
Abstract \\ Voltage dips are considered to be one of the costliest of all power quality disturbances due to their \\ disruption of industrial and commercial operations. The ability to characterise the voltage dip \\ performance of distribution networks has many benefits for industry. There is considerable potential for \\ industry to make large economic gains if voltage dip behaviour can be better understood and planned for. \\ To put strategies in place to deal with voltage dips, there is a need for extensive data collection and \\ analysis so that correct planning decisions can be made. This study details the characteristics of voltage \\ dip data which has been collected at low-voltage sites in Australia over a 9 year period. The data is \\ displayed in a number of different formats to aid analysis.
}

\section{Keywords}

power, quality, disturbances, characteristics, australia, low, voltage, dips, sites

\section{Disciplines}

Engineering | Science and Technology Studies

\section{Publication Details}

S. Elphick, V. Smith, V. Gosbell, S. Perera, P. Ciufo \& G. Drury, "Characteristics of power quality disturbances in Australia: Voltage dips at low-voltage sites," IET Generation, Transmission and Distribution, vol. 9, (15) pp. 2382-2388, 2015.

\section{Authors}

Sean T. Elphick, Victor W. Smith, Victor J. Gosbell, Sarath Perera, Philip Ciufo, and Gerrard M. Drury 


\title{
Characteristics of Power Quality Disturbances in Australia: Voltage Dips at LV Sites
}

\author{
Sean Elphick, Vic Smith, Vic Gosbell, Sarath Perera, Phil Ciufo, Gerrard Drury \\ School of Electrical, Computer and Telecommunications Engineering, University of Wollongong, Wollongong, \\ Australia
}

\begin{abstract}
Voltage dips are considered to be one of the costliest of all power quality disturbances due to their disruption of industrial and commercial operations. The ability to characterise the voltage dip performance of distribution networks has many benefits for industry. There is considerable potential for industry to make large economic gains if voltage dip behaviour can be better understood and planned for. In order to put strategies in place to deal with voltage dips, there is a need for extensive data collection and analysis so that correct planning decisions can be made. This paper details the characteristics of voltage dip data which has been collected at low voltage sites in Australia over a 9 year period. The data is displayed in a number of different formats to aid analysis.
\end{abstract}

Index Terms — Power Quality, Voltage Dip, Voltage Sag, Power Quality Monitoring

\section{INTRODUCTION}

There is a strong argument that voltage dips are the most costly of all power quality disturbances [1]. While perhaps not individually as costly as interruptions, voltage dips are much more prevalent. Even relatively shallow voltage dips can lead to disruption of manufacturing processes due to equipment being unable to operate correctly at the reduced voltage level. Industrial equipment such as variable speed drives and some control systems are particularly sensitive to voltage dips [2]. In many manufacturing processes, loss of only a few critical pieces of equipment (e.g. a programmable logic controller) may result in a full shut down of production, leading to severe financial losses. For some thermally sensitive processes, a significant loss of material as well as the time taken to clean up and restart the process must also be considered. Studies presented in [3] and [4] indicate that the financial losses due to a single voltage dip may run into the millions of dollars depending on the type of industry. For example, [4] states that voltage dips cause $\$ 20$ billion of losses per year to the US economy. From these figures, it is apparent that voltage dips have a significant economic impact. Consequently, if voltage dip behaviour can be better understood and measures put in place for effective mitigation or management, there is considerable potential for significant economic gains to be made. However, as with any mitigation strategy, it is important that the correct level of mitigation be installed as over investment in mitigation is wasted capital. In order to design effective and efficient mitigation and management strategies it is essential to have accurate data. 
While there have been many studies such as [5] and [6] which examine the characteristics of voltage dips based on simulation and statistical analysis, there are few studies that examine voltage dip behaviour based on significant amounts of measured data from a significant number of sites for a significant time period. While studies such as those presented in [7], [8] and [9] do fulfil this criteria, most are now quite dated and may not be relevant to Australian and similar distribution networks. One system that is performing large scale long term dip monitoring is the Italian QuEEN power quality (PQ) monitoring system as described in [10]. This system contains approximately 600 sites and has been operating for approximately 10 years.

Using the data collected as part of a large long term power quality monitoring project, the current research provides a comprehensive analysis of the characteristics of voltage dips in Australia based on practical monitored data. This information can be used by both electricity distributors and customers to aid in understanding of the voltage dip behaviour characteristics of Australian and similar (for example, European) electricity networks.

Proactive monitoring of power quality across Australia has been undertaken since 2002 through the Australian Long Term National Power Quality Survey (LTNPQS) as described in [11] and [12]. Since its inception, the LTNPQS, which is based at the University of Wollongong, has grown to include data from over 3300 sites provided by 12 of the 16 Australian electricity distribution utilities. These sites include a mix of low voltage (LV) (230 V nominal L-N) and medium voltage (MV) (6.6 kV $132 \mathrm{kV} \mathrm{L-L}$ for the purposes of the project) sites. On the whole, there are 4150 monitor-years of data from LV sites available in the database. Utilities that currently participate or have participated in the LTNPQS project supply electricity to at least $90 \%$ of the population of Australia.

The remainder of this paper is arranged as follows: Section 2 describes the voltage dip data that has been collected and analysed in this paper. The concepts of phase and time aggregation, which are used to prevent voltage dips due to the same root cause being counted as multiple events, are important to the analysis of voltage dip data. The methodology that is used for voltage dip aggregation used in this study is also described. Finally, Section 2 details the analysis and reporting methods which have been applied to the data.

Section 3 of the paper details the characteristics of voltage dips in Australia based on the collected data outlined in Section 2. The data is presented in a number of analysis and reporting formats in order to provide a complete visualisation of the voltage dip behaviour.

Section 4 of the paper explores voltage dip performance based on site classification. For the purposes of this study, the available 
sites have been classified by their predominant network construction. The site classifications used closely match those used in distribution system reliability reporting in Australia. Conclusions and recommendations for further research are presented in Section 5.

\section{VOLTAGE DIP ANALYSIS AND REPORTING}

\subsection{Available Data}

The LTNPQS project has collected a significant quantity of data from LV sites since July 2004. In total, approximately 4150 monitor-years of data is available for analysis (1 monitor-year is equivalent to data being collected from one site for one year). There are over 450,000 voltage dips included in the data being analysed in the current research. The voltage dip data has the following characteristics:

- Data is available from $1^{\text {st }}$ July $2004-30^{\text {th }}$ June 2013. The data collected includes the dip timestamp and depth and duration below the dip threshold for each phase on which a dip is detected.

- Data has been collected from 2556 distinct sites.

- These sites are predominately located at distribution (MV/LV) transformers and are connected to the LV terminals. The sites are supplied by a mix of network types (underground and overhead) and supply a mix of predominant loads including residential, commercial and industrial.

- The data included for analysis is limited to voltage dips of residual voltage greater than $0 \%$ and less than $90 \%$ of nominal voltage $(230 \mathrm{~V})$. Duration of dips is restricted to being between $0.01 \mathrm{~s}(1 / 2 \mathrm{a}$ cycle at $50 \mathrm{~Hz})$ and $60 \mathrm{~s}(3000 \mathrm{cycles}$ at $50 \mathrm{~Hz})$.

- Where sites do not have measured data for an entire year, voltage dip data has been annualised (i.e. converted to an equivalent yearly value) so that the data reported by each site is expressed in dips per year. Annualisation is achieved by calculating the period of the year for which the site was monitored and using this value to scale the voltage dip data accordingly. While this method is somewhat crude, since most of the sites have been monitored for the majority of the year, it is only expected to have a modest impact on outcomes.

\subsection{Methods of Analysis}

There have been many methods of analysing and reporting voltage dips proposed over the years. These generally fall into two categories; tabular based methods such as the UNIPEDE Disdip tabular format [13], the ESKOM Voltage Dip Window [14] and dip indices such as that described in [15]. To date, no one format has been settled on by the international community. Many of the tabular reporting formats have deficiencies as they are complex, may be dated and do not readily relate performance to the impact on equipment connected to the network. Complexity and the inability to relate the data to equipment impacts have limited 
the application of many dip indices. Two methods of voltage dip analysis and reporting have been utilised in the current research. These are the Sag SAIFI index [16] and reporting in the EN50160 format [17]. The Sag SAIFI method has been selected because it takes into account both dip depth and duration in order to relate dip behaviour with equipment impacts. The index also has a synergy with reliability, allowing a comparison of dip performance with interruption performance. EN50160 format has also been selected as it is modern and is incorporated in standards utilised in much of Europe along with other parts of the world. Both of the aforementioned methods are described in detail in the following sections.

2.2.1 Sag SAIFI: For the LTNPQS project, a special index termed Sag SAIFI has been specifically developed for reporting of voltage dips. This index, which is fully described in [16], provides a measure of the impact of voltage dips on equipment and equates the impact of voltage dips to that of interruptions. A Sag SAIFI value of 1 indicates that the voltage dip will have an equivalent impact on equipment to that of an interruption; i.e. all equipment will trip off or reset. While voltage dips will not persist as long as interruptions and do not involve a reduction of voltage to $0 \mathrm{~V}$ (i.e. an outage), in some cases, a severe voltage dip may have similar impact. For example, in continuous process manufacturing, any tripping of equipment may result in a major disruption of the process and a significant downtime and waste of raw material before the process can be restarted. In [18], it is stated that up to $27 \%$ of the cost of an interruption to a manufacturing industry occurs within the first seconds of the interruption.

For the Sag SAIFI calculation, concepts of time and phase aggregation have been applied to all voltage dip data so that the same voltage dip occurring across several phases or at several time stamps close together (or both) (such as multiple dips due to the same fault occurring due to recloser operations) are not reported multiple times. For the current research, voltage dip time and phase aggregation is implemented as follows:

- Phase Aggregation - Phase aggregation involves reducing dips on multiple phases with the same timestamp to one equivalent dip. Phase aggregation is implemented as follows; for dips with the same timestamp across multiple phases, the Sag SAIFI index is calculated for each phase on which a dip is recorded. This can result in up to three indices (one for each phase). Once this has been undertaken, the retained dip data (timestamp, residual voltage and duration) is the data which corresponds to the largest Sag SAIFI index. This method is considered superior to other methods of aggregation which only examine the depth of the dip (e.g. retaining the deepest dip), such as that proposed in [19], due to the fact that this method recognises that a long, relatively shallow dip may have the same or greater impact on equipment as a short deep dip. 
- Time Aggregation - Time aggregation involves reducing dips that occur close together in time to a single equivalent dip. Time aggregation is performed after phase aggregation and is implemented as follows; a one minute fixed window is applied to the dip data. This window begins at the timestamp of the first dip being examined. Any further dips within this one minute window are subject to the time aggregation process. Using phase aggregated data, the equivalent single dip during the one minute window is the dip which produced the largest Sag SAIFI index within the one minute window.

2.2.2 EN 50160 Format: EN 50160, "Voltage characteristics of electricity supplied by public electricity networks" [17], employs a tabular method of classifying and reporting voltage dips based on their retained voltage and duration. The method of dip classification from EN 50160 is shown in Table 1.

\subsection{Concept of the Average and $95^{\text {th }}$ Percentile Site}

When examining the performance of an entire population, it is customary to apply statistical measures across the population (i.e. across the indices from all the individual sites). Two statistical measures have been selected for use in this paper. These are the arithmetic average (Average) which gives an indication of average performance and the $95^{\text {th }}$ percentile which gives an indication of performance which are amongst the worst performing (sometimes referred to as worst served customers).

\subsection{Site Classification}

The LTNPQS includes classification of monitored sites based on the predominant construction of the network which supplies the site and the proximity of the site to the transformer terminals; also known as site strength. For strength classification, sites close to the transformer LV terminals are classified as strong while those remote from the transformer terminals are classified as weak. A site is classified as weak if it is sufficiently removed from the transformer that the fault level is half of that at the transformer terminals. Depending on the conductor, this may only be a matter of metres at LV. The LTNPQS uses the following site classifications, which are aligned with the classification of sites used for distribution system reliability assessment in Australia:

- City - Predominantly short underground feeders. Ring systems.

- Suburban - Predominantly short overhead feeders and distributors but including some underground feeders and distributors.

- Short Rural - Predominately longer overhead feeders and distributors.

- Long Rural - Long to very long overhead feeders and distributors to remote locations. 
Table 1: Voltage Dip Classification and Reporting According to EN 50160 [17]

\begin{tabular}{lccccc}
\hline $\begin{array}{l}\text { Residual } \\
\text { Voltage } \boldsymbol{u}\end{array}$ & $\mathbf{5} \leq \mathbf{t} \leq \mathbf{2 0 0}$ & $\mathbf{2 0 0}<\mathbf{t} \leq \mathbf{5 0 0}$ & $\mathbf{5 0 0}<\mathbf{t} \leq \mathbf{1 0 0 0}$ & $\mathbf{1 0 0 0}<\mathbf{t} \leq \mathbf{5 0 0 0}$ & $\mathbf{5 0 0 0}<\mathbf{t} \leq \mathbf{6 0 0 0 0}$ \\
\hline $\boldsymbol{\%}$ & $\mathbf{m s}$ \\
\hline $90>\mathrm{u} \geq 80$ & CELL A1 & CELL A2 & CELL A3 & CELL A4 & CELL A5 \\
$80>\mathrm{u} \geq 70$ & CELL B1 & CELL B2 & CELL B3 & CELL B4 & CELL B5 \\
$70>\mathrm{u} \geq 40$ & CELL C1 & CELL C2 & CELL C3 & CELL C4 & CELL C5 \\
$40>\mathrm{u} \geq 5$ & CELL D1 & CELL D2 & CELL D3 & CELL D4 & CELL D5 \\
$5>\mathrm{u}$ & CELL X1 & CELL X2 & CELL X3 & CELL X4 & CELL X5 \\
\hline
\end{tabular}

\section{Characteristics of Voltage Dips in Australia}

\subsection{Voltage Dip Depth and Duration Characteristics}

A commonly used method of visualising voltage dip performance is to display the data on a residual voltage vs. duration plane. Fig. 1. shows such a representation, overlaid with the ITI curve [20], for the data set which is being analysed. It is clear that voltage dips occur across the entire voltage/duration plane. With respect to the ITI curve, which is often used as a design guide for equipment voltage dip immunity, the number of points below the curve clearly indicate that the network performance cannot meet the ITI curve requirements. Consequently, the fact that while equipment may be designed alongside the ITI curve, it does not mean that this equipment is immune to the range of voltage dips likely to be experienced on electricity distribution networks. On the whole, $22 \%$ of the measured voltage dips shown in Fig. 1. fall below the ITI curve.

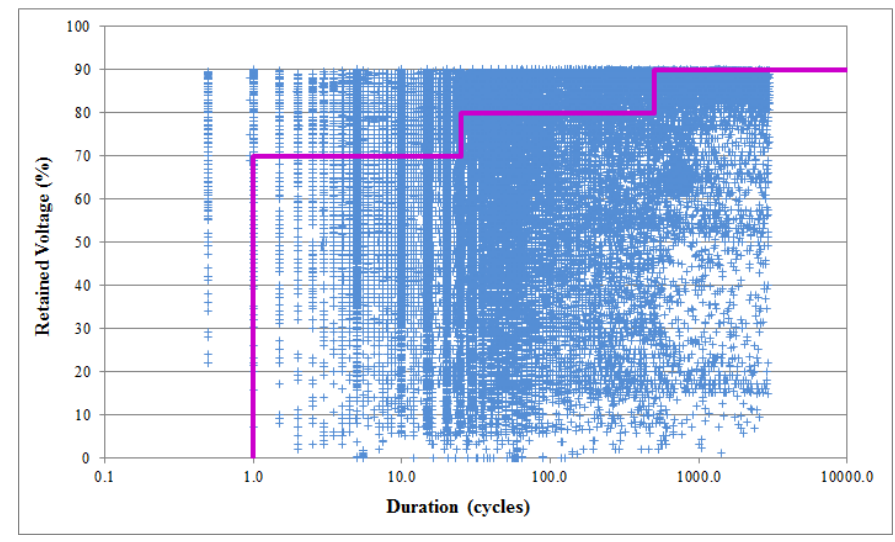

Fig. 1. Voltage Dip Residual Voltage vs Duration Plot overlaid by ITI Curve

In order to address the disconnect between equipment immunity and network performance, a number of European organisations have introduced the concept of 'responsibility sharing' [21]. Under this arrangement, curves are given in the voltage-time plane which subdivide the plane into areas of responsibility for equipment manufacturers and network operators. The benefit of these curves is that they aim to provide a relationship between network and equipment performance; something lacking in the ITI curve visualisation technique. A generic example of such a curve, adapted from [21], is shown in Fig. 2a. In the figure, the 
voltage-time plane has been divided into three segments. Equipment immunity to very short dips, which network operators have little control over, Area A, are the responsibility of the installation. Area B defines an area where the network operator must limit the number of dips but the installation must also be aware that they can occur and can choose to take action to mitigate them. The area of the plane defined by Area $\mathrm{C}$ is a region where network operators are not permitted to allow dips to occur. In this region, it is the protection settings and other network design features which are controlled by the network operator that will define the dip characteristics. Fig. 2b. shows a specific set of responsibility curves according to Swedish regulation for networks operated at $45 \mathrm{kV}$ or less [21].

Fig. 2c. shows the voltage dips from the LTNPQS overlaid by the responsibility sharing curves shown in Fig. 2b. In the figure, it appears that the bulk of dips occur in region B of Fig. 2a. However, it is not immediately obvious that there is a very large number of dips in region A of Fig. 2a. which are effectively graphed on top of each other. In fact, overall, the bulk of dips $(60.12 \%)$ do lie in the responsibility region where installations should tolerate dips (Area A of Fig. 2a.). This is the region where the network operator has little control over dips and if installations wish to continue to operate during the dips in this region, they should either ensure that equipment has sufficient immunity to the dips or take measures to mitigate the dips. $38.12 \%$ of dips are found to occur in region B of Fig. 2a. and only a very small number (1.76\%) of dips are found to occur in region C.

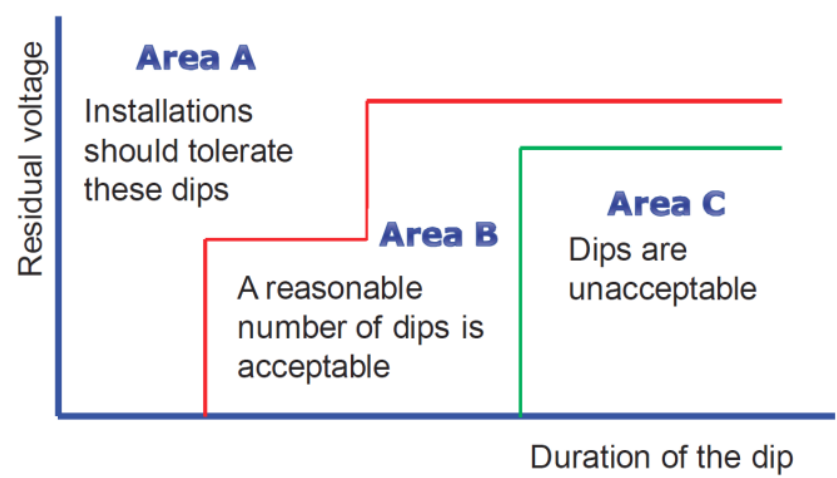




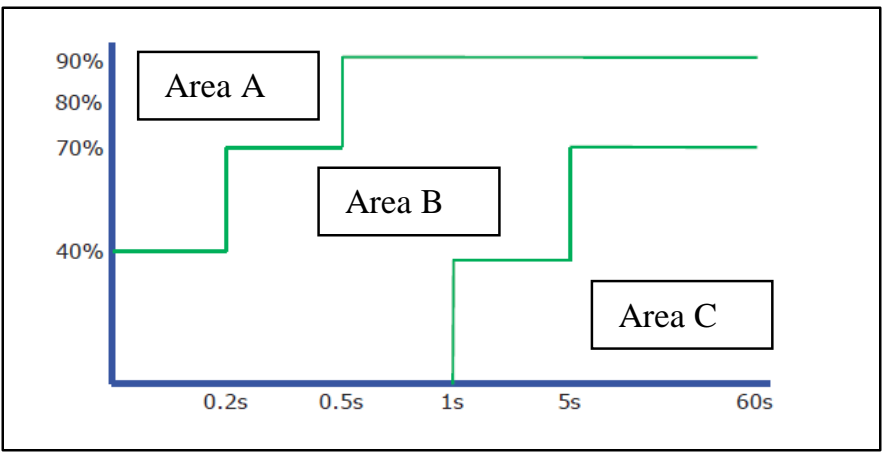

$b$

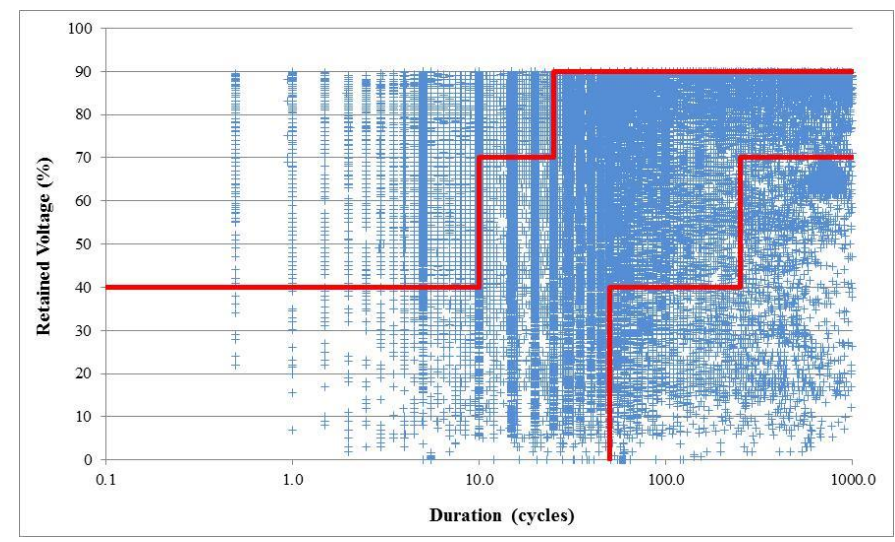

$c$

Fig. 2. Dip Responsibility Sharing Curves

a Generic Dip Responsibility Sharing Curves [21]

$\mathrm{b}$ Limits according to the Swedish Regulation for Networks with $45 \mathrm{kV}$ and less modified from [21]

c LTNPQS Voltage Dip Data overlaid by Swedish Regulation Responsibility Sharing Curves

The curves shown in Fig. 2a. and Fig. 2b. are analogous to the voltage sag protection curve [22] developed for the LTNPQS project and shown along with the voltage dip data in Fig. 3 The sag protection curve is designed to provide an indication of the capability of the network with respect to voltage dip performance based on typical overcurrent protection settings. This is advantageous compared to other methods of visualisation as the capability of the network with respect to voltage dips is clearly illustrated by the protection curve. Ostensibly, the network operator has little capability to mitigate voltage dips to the left of the curve but can control protection settings to reduce the number of voltage dips to the right of the curve. From first impressions, it appears that the bulk of dips occur to the right of the protection curve. However, Fig. 3. Suffers from the same visualisation problems as Fig. 2c in that many dips are graphed on top of each other. In fact, analysis of the LTNPQS data indicates that only $22 \%$ of voltage dips are to the right of the protection curve. 


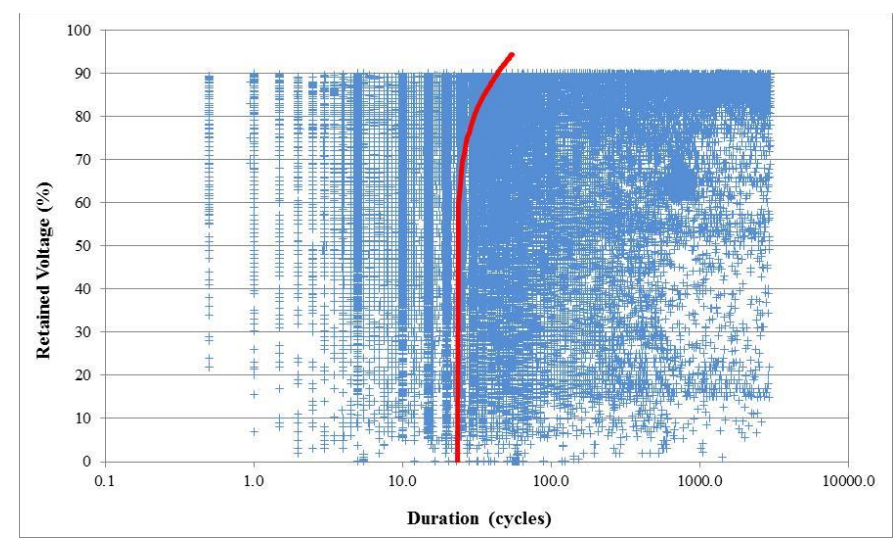

Fig. 3. Voltage Dip Data overlaid by Voltage Sag Protection Curve [22]

It can be difficult to obtain insight from the data shown in Fig. 1., Fig. 2c. and Fig. 3., due to the volume of data shown. To address this difficulty, a number of alternative methods of voltage dip characterisation have been applied. Fig.4a. shows a histogram of residual voltages. The figure shows that the vast majority of voltage dips are quite shallow, being above $70 \%$ of the residual voltage. These dips are the result of either shallow reflected faults or possibly the starting of large loads, such as directon-line connected motors.

Fig. 4b. shows a histogram of dip durations. Two distinct clusters of duration can be identified. These are the groups on the left of the graph and the groups on the right of the graph. The first cluster of short duration values (to approximately six cycles) have characteristics to indicate that they are faults in the upper MV network (33 $\mathrm{kV}$ and above) which are cleared very quickly by unit protection and other fast acting sub-transmission protection schemes. The second cluster of longer duration values has characteristics which can be attributed to one of two causes; voltage dips in other parts of the MV network which have slower overcurrent and distance protection schemes, and subsequently longer fault clearing times, or starting of large loads such as direct-on-line connected motors, such as those found in air conditioning units.

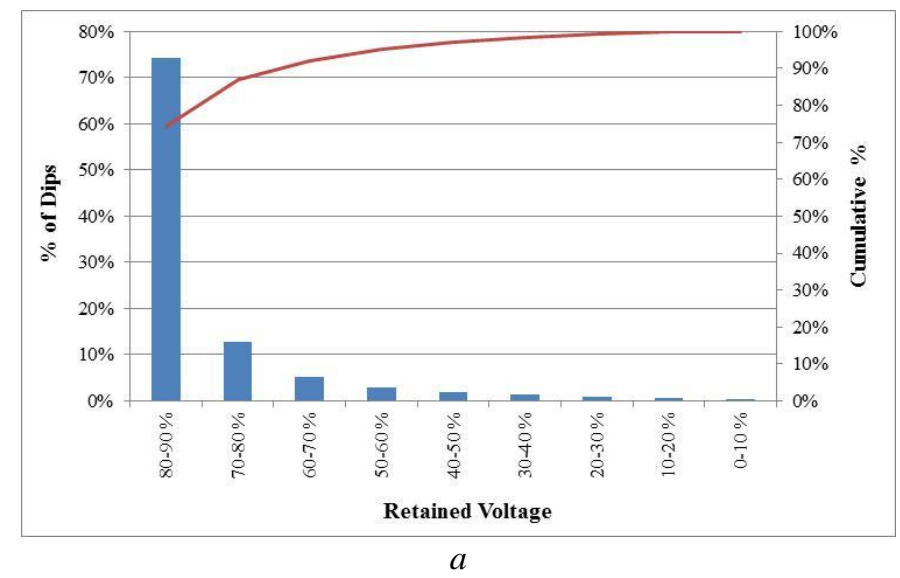




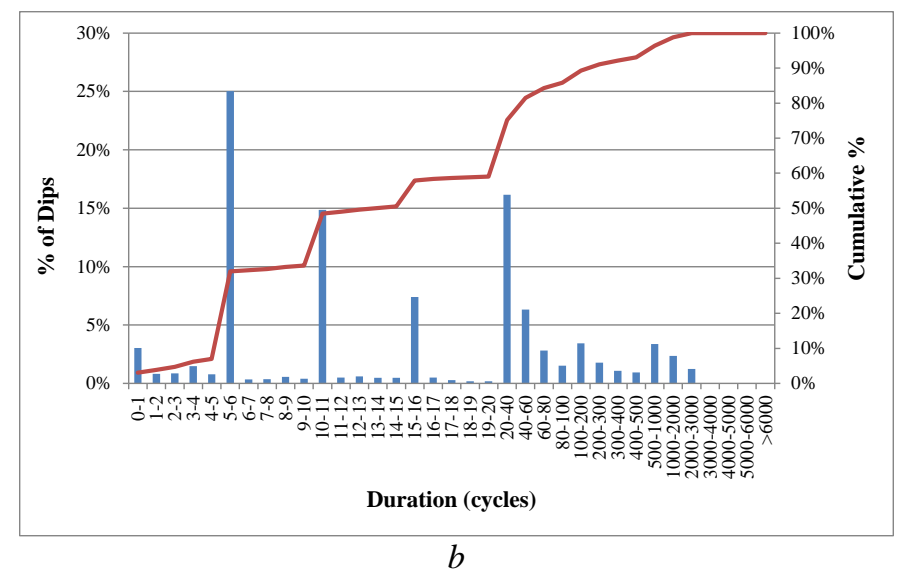

Fig. 4. Histograms of Voltage Dips

a retained voltage

b Duration

Fig. 4 does not provide insights into any relationship between the residual voltage and the duration of the voltage dips. This is addressed in Fig. 5a. which shows the voltage dip data plotted three dimensionally. Somewhat surprisingly, Fig. 5a. shows that the majority of dips are short and shallow. Intuitively, it would be expected that the short dips would be deeper indicating almost instant protection operation. However, this is not found to be the case with shallows dips in evidence at all durations. Fig. 5 b. shows the same data as in Fig. 5a. but with the $0.8-0.9$ p.u. voltage dips removed in order to illustrate the retained voltage and duration performance of the deeper dips. 


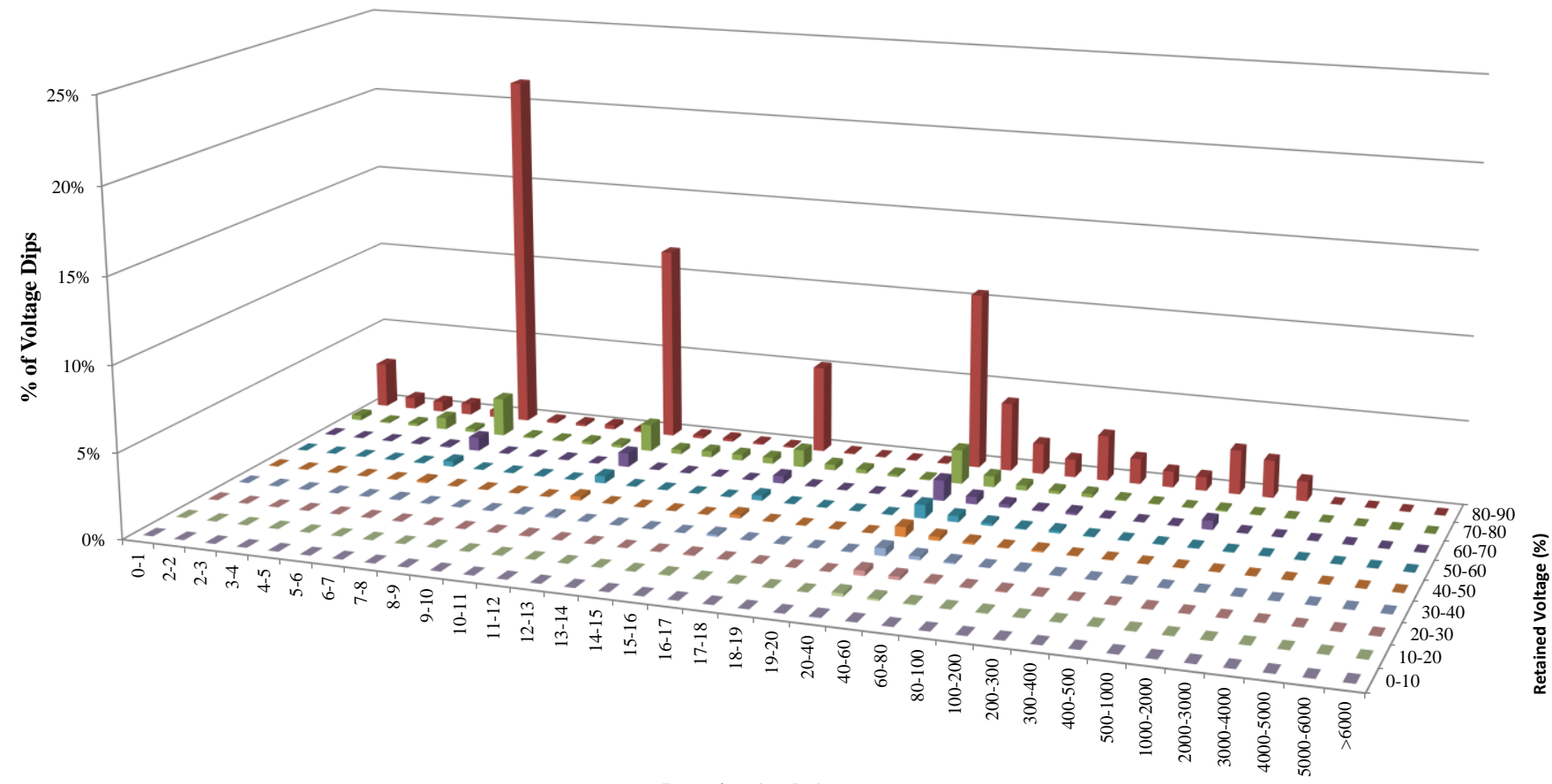

Duration (cycles)

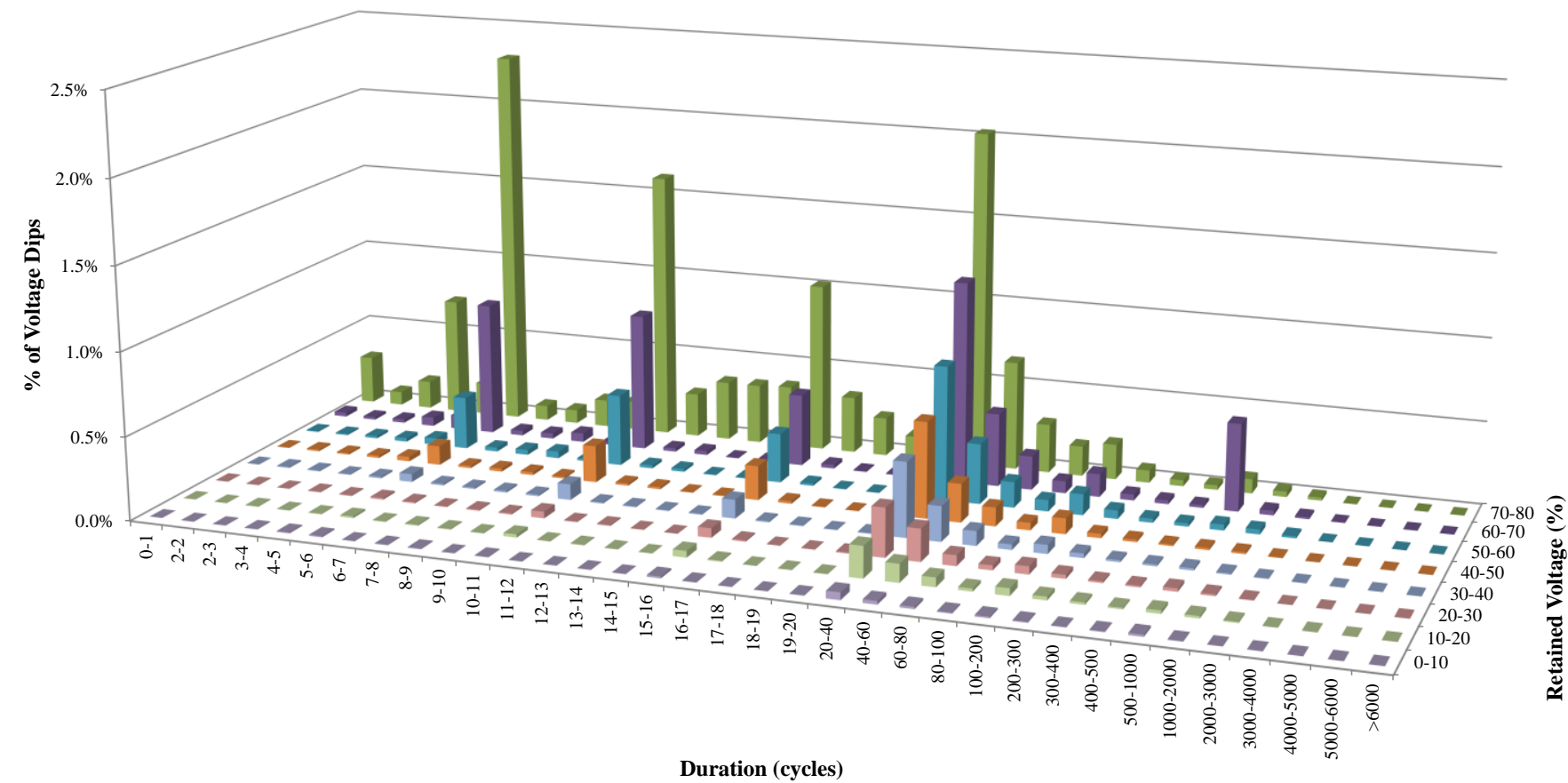

$b$

Fig. 5. 3-D Plot of Voltage Dip Residual Voltage and Duration a All data 


\subsection{Sag SAIFI Format}

Fig. 6. shows the yearly trend of Sag SAIFI for the available data. It can be seen that the trend is highly variable. There are a number of explanations for the variability in the trend of dips. The most obvious is the fact that the incidence of dips is generally highly dependent on prevailing weather conditions (e.g. prevalence of storms and high winds). Other factors impacting dip behaviour can include variations in network maintenance such as tree trimming programs. A full examination of the variability of the dip trend is beyond the scope of this paper and may be considered in future work.

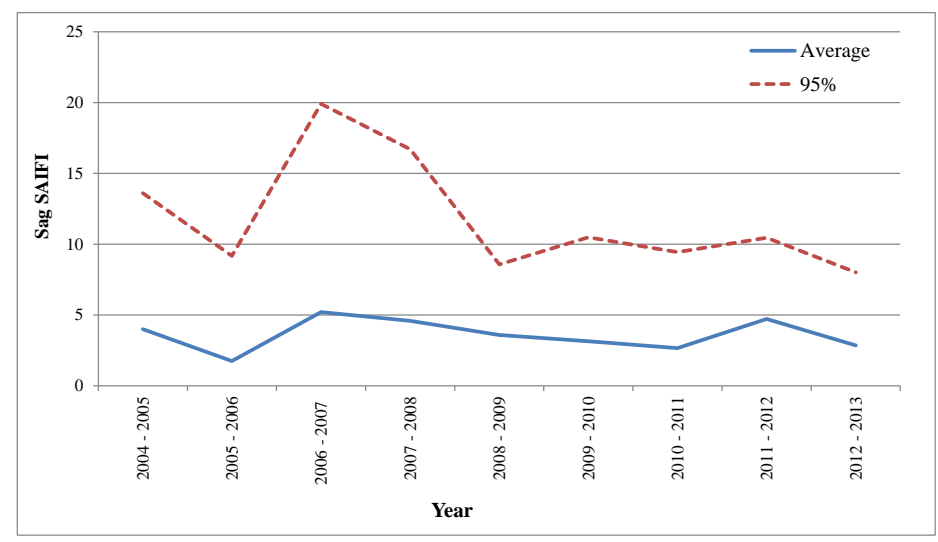

Fig. 6. Yearly Sag SAIFI Trend for LV Sites

Taking the average across all years, the average Sag SAIFI is 3.3 and the $95^{\text {th }}$ percentile Sag SAIFI is 11.2. This means that the average site will experience dip activity which is severe enough to be equivalent to 3.3 losses of supply per year. Similarly, the $95^{\text {th }}$ percentile site will experience dip activity with a severity equivalent to 11 losses of supply per year. These values are in contrast to reliability figures shown in [23] which indicate that System Average Interruption Frequency Index (SAIFI) of the number of outages at a site each year is less than 2 across the whole country. Consequently, it is clear that customers will experience a greater number of effective supply outages due to voltage dips than due to permanent faults which are reported in reliability indices. While it is accepted that the effective outages caused by voltage dips will not persist as long as the supply outages, an effective outage due to a voltage dip can have a very similar impact to a short outage for some industries due to the fact that once a plant or process has tripped it takes s significant amount of time to restart. 


\subsection{EN50160 Characterisation for Australian Voltage Dips}

This section details the overall performance of sites across all of the data that is available. The data is arranged based on the EN50160 reporting format as outlined in Section 2.2.2. Fig. 7. shows the percentage of all voltage dips which fall into each EN50160 reporting category for the entire data set which is being examined in the current research. It can be seen that the majority of dips are short and shallow. There are very few dips which are deep.

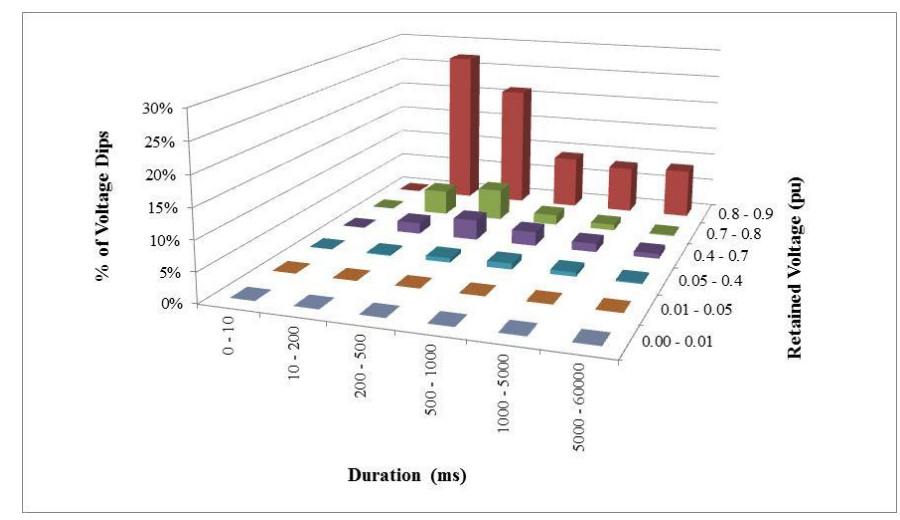

Fig. 7. Percentage of Voltage Dips which fall into each EN50160 Reporting Category

Fig. 8a. shows the number of voltage dips per site per year for the average site. The values in this figure are calculated as follows:

- The number of voltage dips at the average site for each year is calculated for each reporting category. This results in nine (2004 - 2013) values for the average site for each reporting category.

- The overall value displayed in the figure is the arithmetic average of these nine values.

Fig. 8b. shows the same information as Fig. $8 \mathrm{a}$. for the $95^{\text {th }}$ percentile site. It can be seen that the $95^{\text {th }}$ percentile site has significantly more longer and deeper dips than the average site. For dips in the $0.8-0.9$ p.u. residual voltage range, the $95^{\text {th }}$ percentile site has approximately $50 \%$ more dips than the average site. For dips in the $0.7-0.8$ p.u. and $0.4-0.7$ p.u. residual voltage ranges, the $95^{\text {th }}$ percentile site has between four and six times as many dips as the average site. 


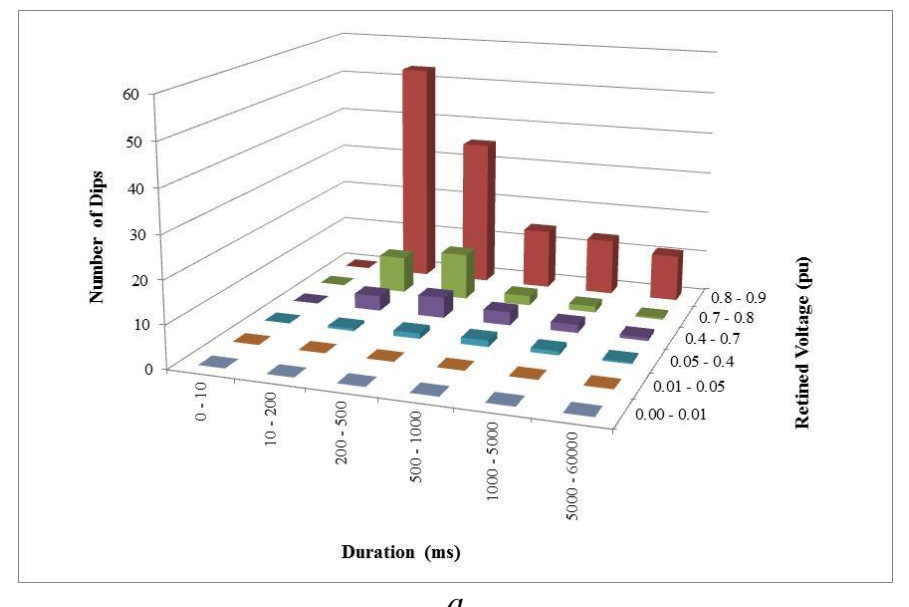

$a$

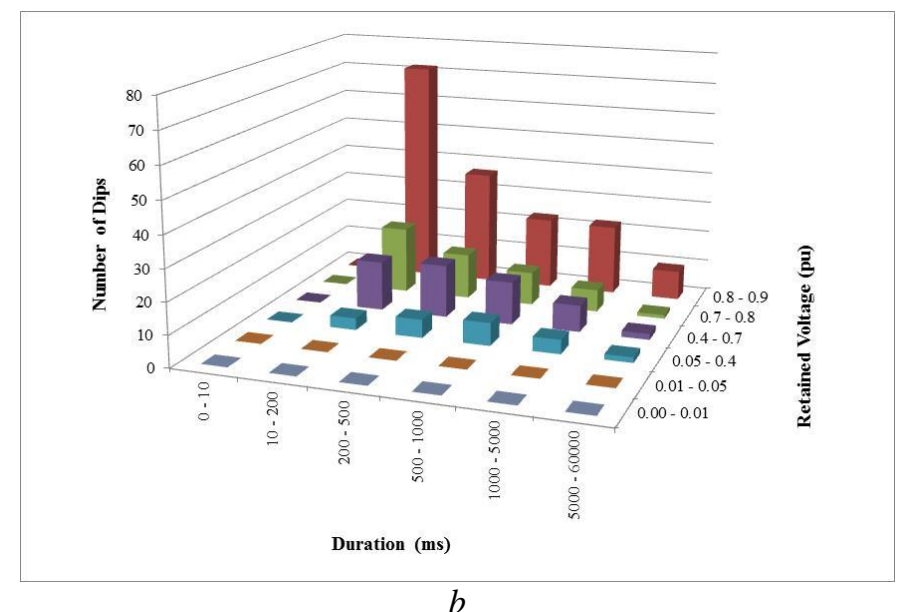

Fig. 8. Number of Voltage Dips per Site per Year in EN50160 Reporting format a for the Average Site

$b$ For the $95^{\text {th }}$ Percentile Site

\section{Voltage Dip Performance by Site Classification}

In this section of the paper, the voltage dip performance is examined based on the site classification types outlined in Section 2.4.

4.1.1 Sag SAIFI Format: Fig. 9. shows Sag SAIFI performance based on the strength and network type classification for each site based on all available data. When the impact of site strength is examined, it can be seen that sites classified as weak have higher Sag SAIFI levels than those classified as strong. For sites classified by network type, those classified as long rural have the worst Sag SAIFI performance, particularly where the $95^{\text {th }}$ percentile value is concerned. This is due to the fact that many of these sites will be supplied by long overhead MV feeders. Such feeders have much higher exposure to dip causing phenomena (e.g. weather, animals, vegetation) than other network types such as city, where the bulk of the distribution is underground. That is, the feeders either have an overall higher fault rate per kilometre or have a similar fault rate but have many more kilometres of line. 


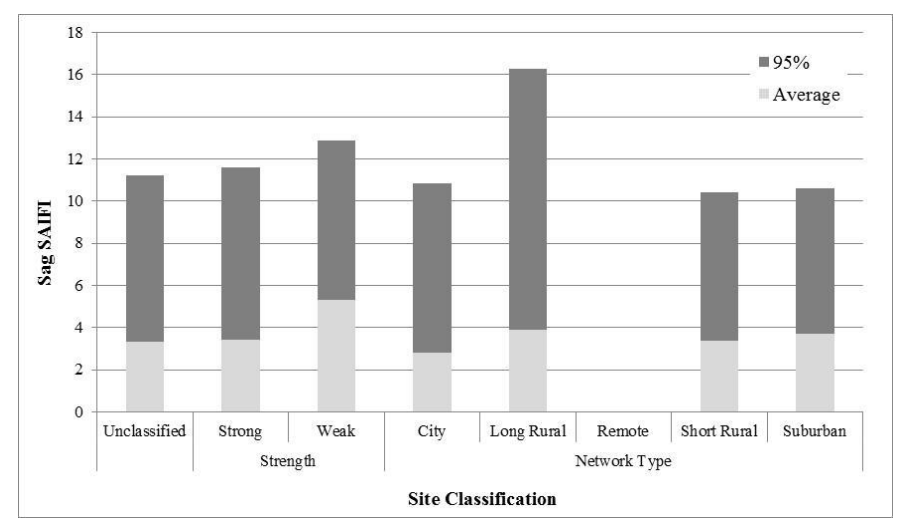

Fig. 9. Sag SAIFI Performance by Site Classification for LV Sites

4.1.2 EN50160 Format: Fig. 10. shows the average percentage of dips which fall into each EN50160 reporting category for residual voltage. Sites classified as city have performance which is somewhat atypical of other site classifications due to the fact that only approximately $45 \%$ of dips fall into the $80-90 \%$ retained voltage reporting category compared to approximately $60 \%$ for other site classifications.

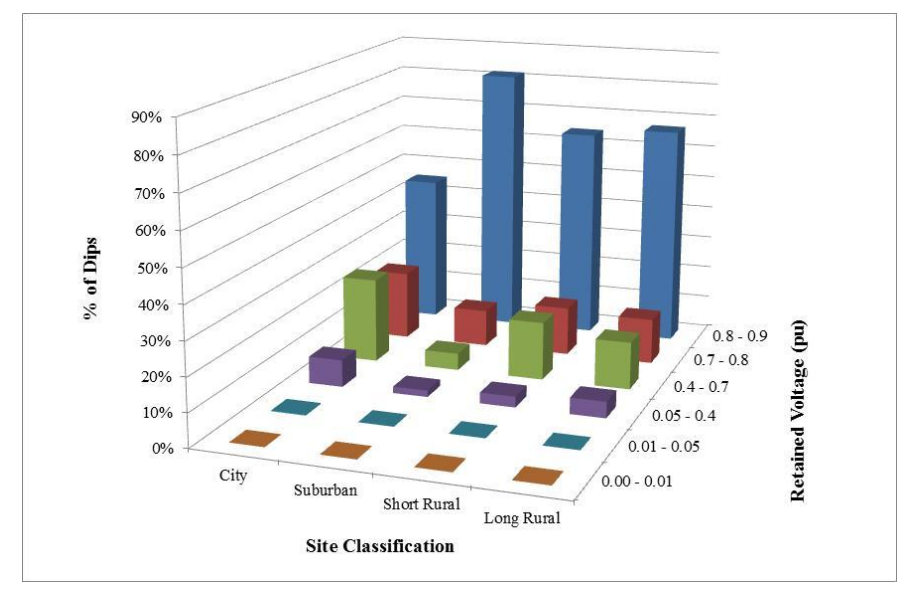

Fig. 10. Overall Percentage of Voltage Dips which fall into each EN50160 Retained Voltage Reporting Category by Site

\section{Classification}

Fig. 11. shows the percentage of voltage dips for each EN50160 reporting format duration category. In Fig. 11., it can be seen that the duration of dips is much shorter for sites classified as city. Overall, the following has been identified:

- Sites classified as suburban have comparatively much longer duration than other site classifications for deep dips in the 1 $-5 \%$ residual voltage reporting category.

- Sites classified as short and long rural show comparatively longer duration for the $5-40 \%$ residual voltage reporting category. 
- There is similar dip duration across suburban, short rural and long rural sites for dips in the $80-90 \%$ residual voltage reporting category.

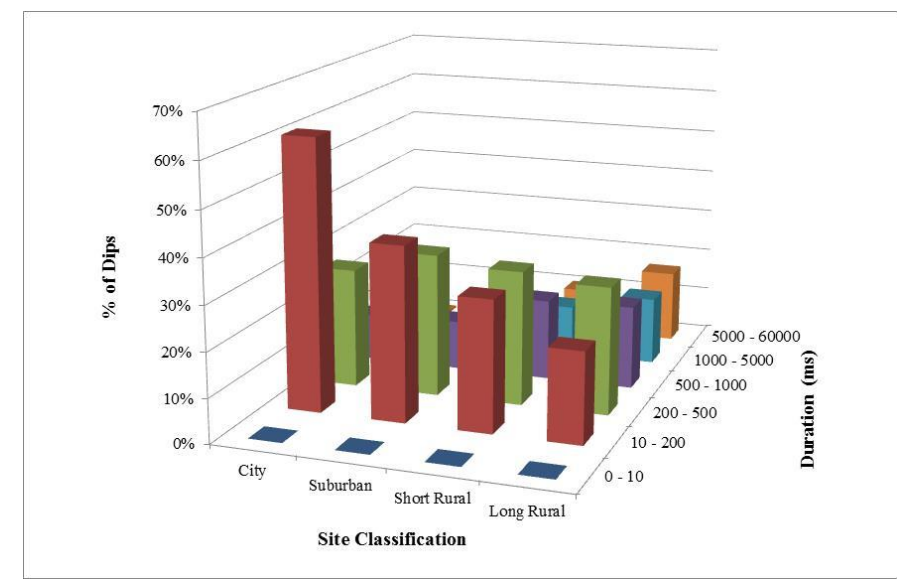

Fig. 11. Overall Percentage of Voltage Dips which fall into each EN50160 Duration Reporting Category by Site Classification

\section{CONCLUSION}

Given the high economic costs associated with interruption of commercial and industrial operations due to voltage dips, successful mitigation of voltage dips may significantly reduce economic losses. This paper described the characteristics of voltage dips measured at a large number of sites over nine years on Australian low voltage networks. A number of analysis techniques have been utilised to understand and visualise the data including the use of the concepts of phase and time aggregation which attempt to calculate an equivalent dip for dips occurring on multiple phases with the same timestamp or occurring close together in time.

Understanding of the characteristics of voltage dips is useful to industry as it allows them to design mitigation strategies based on the actual performance of the electricity distribution network. Industry should be able to use the data presented in this paper to gain a practical understanding of the general performance of the Australian electricity network with respect to voltage dips. This research can be further extended by developing more accurate economic models to reveal the true cost of dips to Australian industry.

\section{REFERENCES}

[1] R. Barr, V.J. Gosbell, S. Perera, "The Customer Benefits of High Reliability and High Power Quality," in EESA Electricity 2005 Conference, Brighton-le-Sands, NSW, Australia, 2005.

[2] Roger C. Dugan, Mark F. McGranaghan, Surya Santoso, H. Wayne Beaty, "Electrical Power Systems Quality", 3rd ed. New York: McGraw Hill, 2012.

[3] David Chapman, "Power Quality Application Guide - The Cost of Poor Power Quality", 2001.

[4] B. H. Chowdhury, Power Quality, IEEE Potentials, vol. 20, no. 2, 2001, pp. 5 - 11. 
[5] M. H. J. Bollen, M. R. Qader, R. N. Allan, "Stochastical and statistical assessment of voltage dips," in Tools and Techniques for Dealing with Uncertainty (Digest No. 1998/200), IEE Colloquium on, 1998, pp. 5/1-5/4.

[6] Mikael Wamundsson, M. H. J. Bollen, "Predicting the number of voltage dips as a function of both voltage and duration," in 13th International Conference on International Conference on Harmonics and Quality of Power, ICHQP 2008, Wollongong, Australia, 2008, pp. 1-6.

[7] Erich W. Gunther, Harshad Mehta, "A Survey of Distribution System Power Quality - Preliminary Results," IEEE Transactions on Power Delivery, vol. 10, no. 1, pp. 322 - 329, January 1995.

[8] A. C. Wang, C. N. Lu, "A Survey of Distribution Feeder Power Quality," presented at the IEEE Power Tech 2005, Russia, 2005.

[9] Douglas S. Dorr, M. Brent Hughes, Thomas M. Gruzs, Robert E. Jurewicz, John L McClaine, "Interpreting Recent Power Quality Surveys to Define the Electrical Environment," IEEE Transactions on Industry Applications, vol. 33, no. 6, pp. 1480 - 1487, 1997.

[10] Riccardo Chiumeo, Luciano Garbero, Liliana Tenti, Chiara Gandolfi, Michele de Nigris, "The Voltage Dip performance Assessment of the Italian MV Network Through Global Indices," presented at the 21st International Conference on Electricity Distribution, CIRED 2011, Frankfurt, Germany, 2011.

[11] S. Elphick, V. Gosbell, R. Barr, "The Australian Power Quality Monitoring Project," in EEA Annual Conference, Auckland, New Zealand, 2006.

[12] S. Elphick, V. Gosbell, V. Smith, R. Barr, "The Australian Long Term Power Quality Survey Project Update," in 14th International Conference on Harmonics and Quality of Power, ICHQP'10, Bergamo, Italy, 2010.

[13] Disdip Group, "Voltage Dips and Short Interruptions in Medium Voltage Public Electricity Supply Systems", Report Prepared for International Union of Producers and Distributors of Electrical Energy (UNIPEDE), 1990.

[14] ESKOM, South African Power Quality Standard NRS 048-2: 1996, 1996.

[15] V.J. Gosbell, D. Robinson, S. Perera, "The Analysis of Utility Voltage Sag Data," in International Power Quality Conference, Singapore, 2002, pp. 479 - 490.

[16] R. A. Barr, V. J. Gosbell, I. McMichael, "A new SAIFI based Voltage Sag Index," in 13th International Conference on Harmonics and Quality of Power, ICHQP2008, Wollongong, Australia, 2008.

[17] CENELEC, Voltage characteristics of electricity supplied by public electricity networks, EN 50160:2010, 2010.

[18] David Lineweber, Shawn McNulty, "The Cost of Power Disturbances to Industrial \& Digital Economy Companies", Report Prepared for EPRI's Consortium for Electric Infrastructure for a Digital Society (CEIDS), June 29, 2001.

[19] Math H. J. Bollen, "Understanding Power Quality Problems Voltage Sags and Interruptions". New Jersey: John Wiley \& Sons, 2000.

[20] Information Technology Industry Council. "ITI (CBEMA) Curve Application Note", last accessed 21st December 2011, Available: http://www.itic.org/resources/iti-cbema-curve/.

[21] M. H. J. Bollen, J. Esteves, K. Brekke, K. Niall, M. Delfanti, "Voltage quality monitoring, dips classification and responsibility sharing," in Harmonics and Quality of Power (ICHQP), 2012 IEEE 15th International Conference on, 2012, pp. 926-931.

[22] R.A. Barr, V.J. Gosbell, S. Perera, "The Voltage Sag Protection Curve," in 12th International Conference on Harmonics and Quality of Power, ICHQP2006, Cascais, Portugal, 2006.

[23] Australian Energy Regulator (AER), "State of the Energy Market", 2013. 